\section{Public must be alert to illegal teeth whiteners and fake training schools}

The BDA has welcomed a BBC investigation revealing the scale of illegal teeth whitening, which has risen by $26 \%$ in the past year.

Undercover reporters from BBC London TV news filmed training schools and companies offering to provide fake whitening qualifications to candidates after just a few hours of training, and putting the public at risk. One school said it had trained '1000s of candidates'

The BBC's film unveils the underhand tactics used by unscrupulous companies to lure naive beauticians and others into believing that they can circumvent the law, when only dental professionals registered with the General Dental Council can legally carry out teeth whitening in the UK.

The schools provide rudimentary guidance for illegal whitening, teaching beauticians and hairdressers how to use whitening gels, powerful heating lights and what treatment and dental advice to offer to customers. The BDA has called on the public to remain alert to the risks.

The BDA also calls on the beauty industry to do more to ensure that its members, and those who train them, are aware that providing tooth whitening treatments can only legally be carried out by a registered dentist or dental care professional.

BDA scientific advisor, Professor Damien Walmsley, said: 'Illegal whitening is now running rampant across the UK, and while authorities are doing what they can it's vital that the public understand the risks.

'We know that sham teeth whitening schools exploit the ignorance of beauticians and others who are unaware that they could end up in a criminal court. Not just that, these untrained operators can permanently damage your teeth and gums and can't provide help if something goes wrong.

'The public need to be aware that fly-by-nights with a few hours online training can cause lasting damage to your teeth and gums and can't help you when something goes wrong.

'If you put yourself in the hands of unqualified individuals armed with unsafe chemicals then you are gambling with your health.

'For safe, effective whitening visit your dentist.'

Dr Ben Atkins, President of the Oral Health Foundation, added: 'While cosmetic treatments like tooth whitening and orthodontics may seem like relatively easy procedures, they are quite the opposite. These are medical procedures and should only ever be carried out by a dental professional.

'The potential repercussions of having these treatments by a non-trained dental professional can be extremely dangerous. There could be a greater risk of infection and cross contamination, as well as permanent damage to the teeth gums, mouth and even the jaw.

'These are the kind of consequences that can last a lifetime, cause unnecessary pain and suffering, and are highly expensive to correct.

'Never gamble with your health. Always see a trained and qualified professional for dental treatment of any kind.'

\section{BDA Benevolent Fund calls for Trustees}

The BDA Benevolent Fund is inviting anyone interested in becoming a Trustee to put themselves forward at the forthcoming AGM.

Keen to ensure the Board represents the needs of all dentists and the wider profession, they are actively keen to hear from

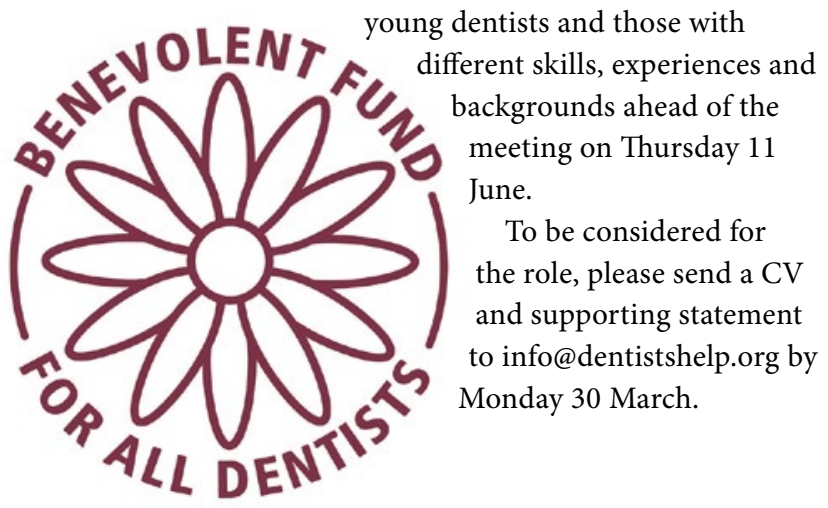

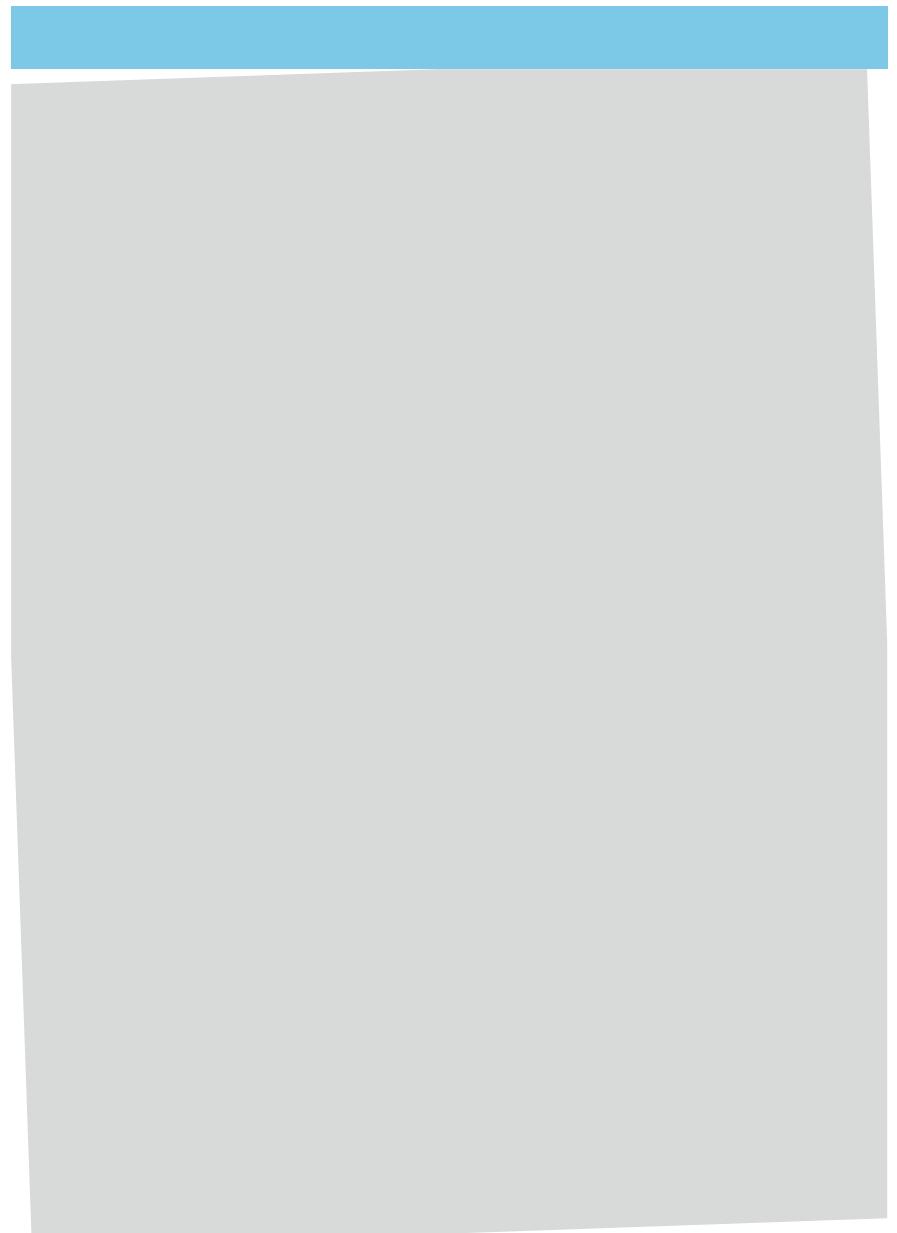

